\title{
Article \\ Graffiti Characterization Prior to Intervention in the Punta Begoña Galleries (Getxo, North of Spain): Raman and XRF Spectroscopy in the Service of Restoration
}

\author{
Idoia Etxebarria ${ }^{1}\left(\mathbb{D}\right.$, Nagore Prieto-Taboada ${ }^{1, *} \mathbb{1}$, Estibaliz Lama ${ }^{2}$, Gorka Arana ${ }^{1}$, María Dolores Rodríguez-Laso ${ }^{2}$ \\ and Juan Manuel Madariaga ${ }^{1,3}$ \\ 1 Department of Analytical Chemistry, Faculty of Science and Technology, University of the Basque Country \\ UPV /EHU, P.O. Box 644, 48080 Bilbao, Spain; ietxebarria027@ehu.eus (I.E.); gorka.arana@ehu.eus (G.A.); \\ juanmanuel.madariaga@ehu.eus (J.M.M.) \\ 2 Department of Painting, Faculty of Fine Arts, University of the Basque Country UPV/EHU, P.O. Box 644, \\ 48080 Bilbao, Spain; estibaliz.lama@ehu.eus (E.L.); mariadolores.rodriguez@ehu.eus (M.D.R.-L.) \\ 3 Unesco Chair of Cultural Landscapes and Heritage, University of the Basque Country UPV/EHU, \\ P.O. Box 450, 01006 Vitoria-Gasteiz, Spain \\ * Correspondence: nagore.prieto@ehu.eus
}

\section{check for}

updates

Citation: Etxebarria, I.;

Prieto-Taboada, N.; Lama, E.; Arana,

G.; Rodríguez-Laso, M.D.; Madariaga,

J.M. Graffiti Characterization Prior to

Intervention in the Punta Begoña

Galleries (Getxo, North of Spain):

Raman and XRF Spectroscopy in the

Service of Restoration. Appl. Sci. 2021,

11, 8640. https://doi.org/10.3390/

app11188640

Academic Editor: Antonella Casoli

Received: 30 July 2021

Accepted: 14 September 2021

Published: 17 September 2021

Publisher's Note: MDPI stays neutral with regard to jurisdictional claims in published maps and institutional affiliations.

Copyright: (c) 2021 by the authors. Licensee MDPI, Basel, Switzerland. This article is an open access article distributed under the terms and conditions of the Creative Commons Attribution (CC BY) license (https:/ / creativecommons.org/licenses/by/ $4.0 /)$.
Abstract: The Historical and Cultural Heritage of Punta Begoña Galleries in Getxo (Bizkaia, North of Spain) are currently in restoration after being abandoned for years. For that reason, many graffiti, which directly affect the wall paintings, appear on most of their walls. Moreover, several graffiti overlap each other, which makes their removal more difficult. For all these reasons, the chemical characterization of these pigments is a priority to optimize the cleaning and consolidation treatments of wall paintings. That being the case, an analysis based on Raman spectroscopy and X-ray fluorescence was carried out to obtain information to help conservators remove the graffiti without damaging the mural paintings and the support. Nevertheless, the first step, using X-ray fluorescence and Raman spectroscopy, involved the need for a database to compare the results and identify the compounds. Thus, different commercial inks were elementally and molecularly characterized to complete the existing databases. After this, an analysis of the inks was carried out that noted the presence of several organic pigments, such as phthalocyanines. Inorganic pigments such as titanium oxide were identified as well. After the analysis, the selection of the best removal process could be carried out to provide the most effective treatment, avoiding the "trial-and-error" classical practice.

Keywords: graffiti; database; Raman spectroscopy; X-ray fluorescence; organic pigments

\section{Introduction}

The Historical and Cultural Heritage of Punta Begoña Galleries in Getxo (Bizkaia, North of Spain) were built in 1918 as a sign of the economic power of the businessman Horacio Etxebarrieta, with the aim of restraining the hillside and creating a private leisure area. The building featured several technological innovations, such as the use of reinforced concrete and other cutting-edge materials for that time [1].

Over the years, the Galleries were abandoned, but recently have been recovered through a multidisciplinary project that aims to restore value to building and the history that surrounds it [2]. The hall room has special relevance as a place of celebrations and events, and currently is in a precarious state of conservation. This hall presents paintings with Francoist iconography related to the wars of the 20th century, but recent studies indicate the presence of original underlying paintings [1]. However, the state of neglect in recent years has led to the presence of numerous graffiti that directly affect the wall paintings and, more importantly, put at risk the conservation of the original mural paintings [1].

For that reason, it is very important to remove the graffiti in a scientific way, avoiding the usual "trial-and-error" method in conservation works, to minimize the impact on the 
support on which they are found. In fact, the stopping of the attacks and damage caused by graffiti on cultural heritage is currently a priority in conservation efforts in general [3-5]. In addition, graffiti generates a vision of abandonment in these places of cultural interest, and usually aid their deterioration due to the interaction with atmospheric agents [6].

Thus, a chemical characterization of the graffiti seems to be essential to propose the best cleaning methodology. The characterization of the pigments is of great help in directing the cleaning and elimination processes for these layers, as well as in evaluating their impact on the compositional materials [7-9]. These paints are generally composed of binders, pigments, fillers, and additives [10].

The chemical characterization of pigments used in graffiti is also crucial in general for the conservation and restoration of urban art, which has increased in recent years in our cities, and not only for the recovery of degraded heritage by anthropogenic factors (vandalism). Two of the most interesting techniques are Raman spectroscopy, for the identification of the molecules composing the different pigments, and X-ray fluorescence (XRF), for the identification of elements present in them [11-14]. Both techniques allow the understanding of the ink's composition in a complementary way.

The first step for the characterization of pigments by Raman spectroscopy involves the need for a valuable database to compare the results. This fact becomes more important when bearing in mind the quick development of the graffiti industry and the associated secrecy. Thus, complete and updated databases are required. In the literature, it is possible to find free databases $[8,9,11,15,16]$, but most of them are not open-access, which limits the possibility of exchanging the information and joining forces. Regardless, there are some interesting open-access databases, such as the Royal Institute for Cultural Heritage database (KIK-IRPA) [15] or the spectral database of the Infrared and Raman Users Group (IRUG) [16], although these reference spectra have been limited to pigments and only a certain number of them, not to specific commercial sprays, which contain a mixture of compounds.

Thus, commercial spray databases would be very relevant, considering aerosol paint manufacturers are reluctant to offer the consumer the overall composition of paints [8,9], usually because each producer keeps its own industrial manufacturing secrets for materials and techniques. For this reason, they only provide the most general composition of their sprays [17]. Nevertheless, if the artists and their most-used sprays are known, the analysis and conservation of their artwork could be easier, or even could help to determine the real authorship of the artwork [9]. It is therefore necessary to create a database containing as many commercial aerosols as possible before beginning any analysis. Taking this into account, it is not only important to have a database with the Raman spectra of a specific pigment, but also relating it to the brand or model of spray, which could provide relevant information and solve the problem of lack of transparency on the part of the industry. Moreover, the elemental information would give important information about the composition of the different brands; for example, allowing their identification. Therefore, the databases of graffiti would be completed and updated with all this information.

On the other hand, the rapid evolution of this industry generates the launch of new sprays and components very often, which could render the databases obsolete. That is why databases, especially for these types of compounds, should be published as open access in order to share, complete, and improve the information available. In this way, the industrial secret problem could be minimized or even settled.

All things considered, the aim of this work was characterizing the graffiti observed in the main hall of the Punta Begoña Galleries by means of Raman spectroscopy and XRF analysis to help restorers to design the most adequate procedure to carry out restoration works. First, 15 different commercial sprays were measured to enlarge the existing openaccess databases found in the literature. 


\section{Materials and Methods}

\subsection{Commercial Sprays Analyses: Database}

Fifteen commercial sprays were selected while considering the colours observed in Punta Begoña's main hall. The selected commercial sprays were different brands. From the Titanlux brand (Tintalux, Barcelona), three sprays of the "spray colour" series were selected: Orange (554), White (566) and Yellow (529). From the Montana brand (Montana Colours, Barcelona) Hardcore series, five sprays were chosen: Vivid Red (RV-3001), Arctic Blue (RV-29), Dark Blue (RV-5005), Druid Brown (RV-246), and Cologno N. Green (RV-237). Finally, from the Decor Pintura brand (ZTHOME, Logroño) seven sprays were analysed: Medium Yellow (ZT107), Light Grey (ZT113), May Green (ZT129), Light Brown (ZT120), Violet (ZT131), Fuchsia (ZT134) and Bordeaux (ZT148).

The sprays were applied on ceramics supports specially made for assays in this project [18]. The mock-ups were $8 \times 10 \mathrm{~cm}$ in size (Figure 1). They were left to dry for 20 days and then collected by scalpel and measured in the same conditions as the inks of the hall room.

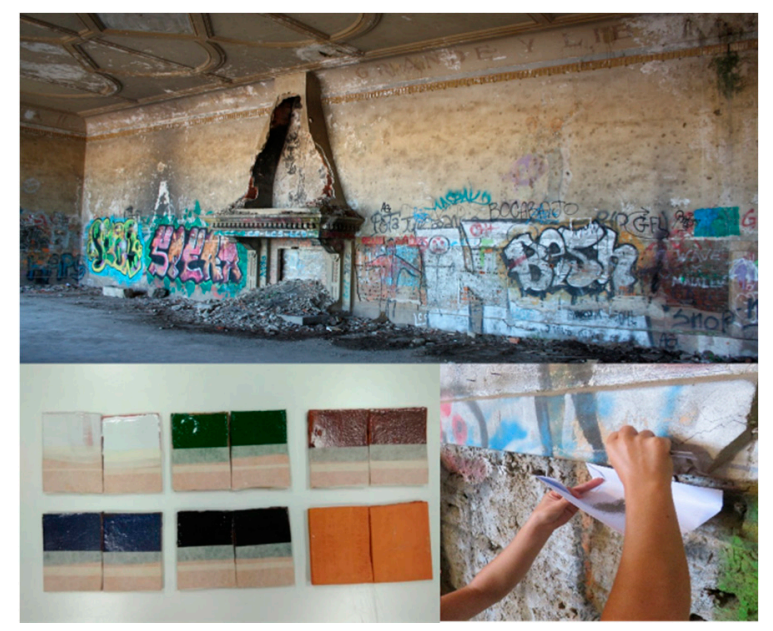

Figure 1. (Top) photograph of the main hall of the Punta Begoña Galleries showing the graffiti covering the entire surface of the marble and mural paintings, up to a height of approximately $2 \mathrm{~m}$; (bottom left) mock-ups with the applied commercial sprays; (bottom right) example of the sampling of the inks in the main hall.

\subsection{Sampling}

The graffiti cover the entire lower part of the main hall. Up to about $1.5 \mathrm{~m}$, the wall is covered with decorative marble, and from that height and above the original mural paintings can be seen. At first, an attempt was made to carry out in situ analysis by portable Raman spectrometer (innoRam laser at $785 \mathrm{~nm}$ excitation, BWTek, Newark, USA) and XRF instrumentation (XMET5100, Oxford Instruments, Abingdon, Oxfordshire, UK). However, the results were poor due to dirt, patina, and fluorescence. For this reason, it was decided to sample the graffiti.

The inks were sampled in the marble area to avoid damaging the paintings, which are in a very precarious state of conservation. For this purpose, and considering that sampling is very restricted, the area with the greatest accumulation of graffiti was chosen to chronologically collect the different types of ink present on the walls and also see the effect of their overlapping. The building has been abandoned for decades, so the results give information for all periods. This could be relevant, due to the changes in the composition of sprays over the years. The layers were scraped by scalpel and collected on different papers to avoid cross-contamination, in an attempt to discriminate between colours or intermediate phases, and disregarding the areas that resembled these intermediate mixtures. As mentioned, the inks were collected consecutively at the same point, the first one being the most modern, and the last one the oldest. The colours collected were: (T1) light red, 
(T2) light green, (T3) dark yellow, (T4) light blue, (T5) light orange, (T6) dark blue, (T7) white, (T8) bone white, (T9) ochre, (T10) dark green, (T11) purple, and (T12) light yellow. Special care was taken in the selection of the specific colours of each ink, without mixing several of them to facilitate their characterisation (Figure 1). Samples were stored in $1.5 \mathrm{~mL}$ Eppendorf tubes until analysis. They were then stored in labelled airtight zip bags.

\subsection{Instrumentation}

The 12 inks collected from the Punta Begoña main hall and the 15 commercial sprays were analysed by Raman spectroscopy and X-ray fluorescence (XRF).

A Renishaw InVia high-resolution micro-Raman spectrometer (Renishaw, UK) was used. The instrument was coupled to a microscope (Leica, Germany) and the objectives used for the measurements were $20 \times, 50 \times$, and $100 \times$ to provide a better focus on the surface. Raman spectra were acquired, in general, between $100-3000 \mathrm{~cm}^{-1}$, with a spectral resolution of $1 \mathrm{~cm}^{-1}$. The lasers used for the analyses were $532 \mathrm{~nm}$ and $785 \mathrm{~nm}$, with a power of $45 \mathrm{~mW}$, although a maximum of $10 \%$ of this power was used in the analyses. A CCD detector cooled by the Peltier effect was used, and the program used by the equipment was the Wire 4.2 software package (Renishaw, Gloucestershire, UK). The treatment of the Raman results was performed by the Omnic 7.2 software (Nicolet).

For elementary analyses, an X-ray fluorescence M4 Tornado (Bruker Nano GmbH, Germany) spectrometer was used. The instrument implemented two Rh tubes mounted on a mechanical collimator (lateral resolution $1 \mathrm{~mm}$ ) and a policapillary optic (lateral resolution $25 \mu \mathrm{m}$ ). The $\mathrm{X}$-ray tube worked at $50 \mathrm{kV}$ and $700 \mu \mathrm{A}$ during the measurements, and $100 \mathrm{~s}$ (lifetime) were considered for each spectral acquisition. The measurements were made under vacuum (20 mbar). To achieve the vacuum, an MV10N VARIO-B diaphragm pump (Vaccubrand, Germany) was used. Relative composition information is provided, using a semiquantitative analysis carried out by the software based on fundamental parameters. The spectral data acquisition and treatment was performed using the M4 software from Bruker.

\section{Results}

\subsection{Commercial Sprays}

The identification of Raman spectra is complex due to the large number of bands, the small differences between different compounds of a similar nature, and problems with obtaining quality spectra. Despite this, it was possible to identify the main pigments of all the commercial sprays by means of Raman spectroscopy, and even some of the bands related to the binders. Moreover, the elemental analysis, which is not so often used in spray characterizations, provided relevant information to better understand their composition.

The results of the XRF analysis of the commercial sprays are collected in Table 1, and molecular information and the spectra obtained by Raman spectroscopy are collected in Table 2 and Figures 2-4. As can be seen in Table 1, most of the commercial sprays had titanium as a major element. This was usually present as titanium oxide in rutile form, a common compound used in sprays as an extenders and opacifier of paints $[7,8]$. However, it was evident that this pattern is not present in the "Decor" brand, in which titanium was not a major element. In fact, in general, in this brand the elemental composition of the spray was more complex. This could be related to the quality of the sprays, since the "Titan" and "Montana" are sprays generally used in street art [6]. Considering the above, the number of major elements was lower, which could indicate: (1) a simpler composition of the mixture; or (2) the use of organic compounds that cannot be analysed by XRF were used in conjunction with rutile as an additive. However, regarding the molecular analysis, it was striking that the identification of rutile [16], despite being the major component in many sprays, was only identified when it was used as pigment as in the case of "White 566" and "Light Grey ZT113", and in a pigment mixture in "Arctic Blue", in which the rutile was mixed with the PB15 phthalocyanine blue [15]. Another remarkable element observed in the XRF analysis was iron, present mostly in sprays of the red and yellow 
palette, and especially in the brown colours "Druid Brown RV-246" and "Light Brown ZT120". In these sprays, Raman spectroscopy revealed a mixture ofiron oxidem, hematite, and iron hydroxide, goethite [16]. Finally, the presence of copper was also significant due to its presence as major element in the "Dark Blue RV-5005" spray, which could indicate the use of a pigment based on this element that is usual in blue colours [19]. As was presumable by the elemental analysis results, the pigment PB15, a copper pthalocyanine, was identified by Raman spectroscopy [15].

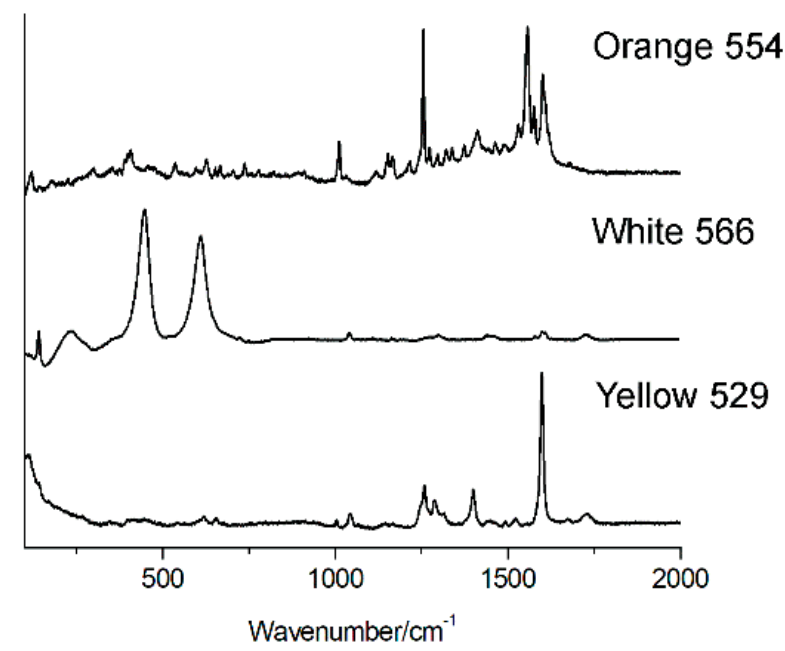

Figure 2. Raman spectra of the commercial sprays of the Titan brand.

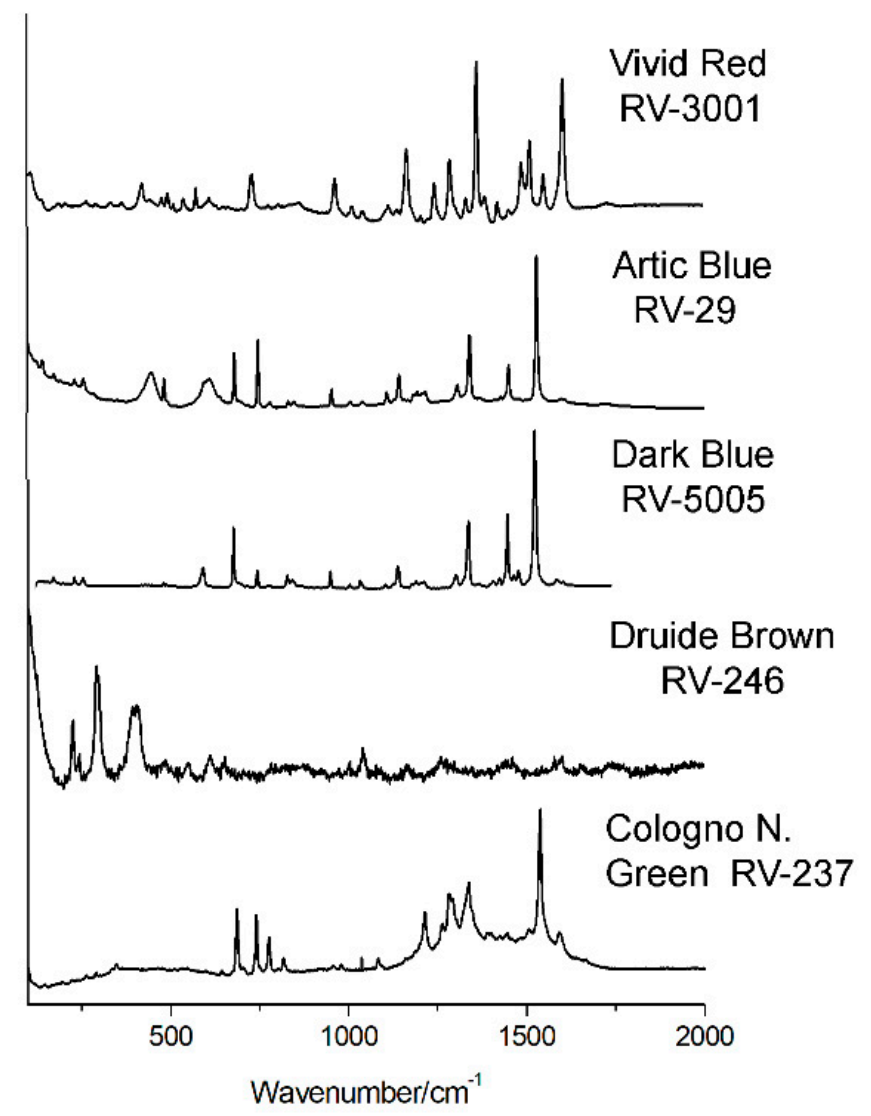

Figure 3. Raman spectra of the commercial sprays of the Montana brand. 


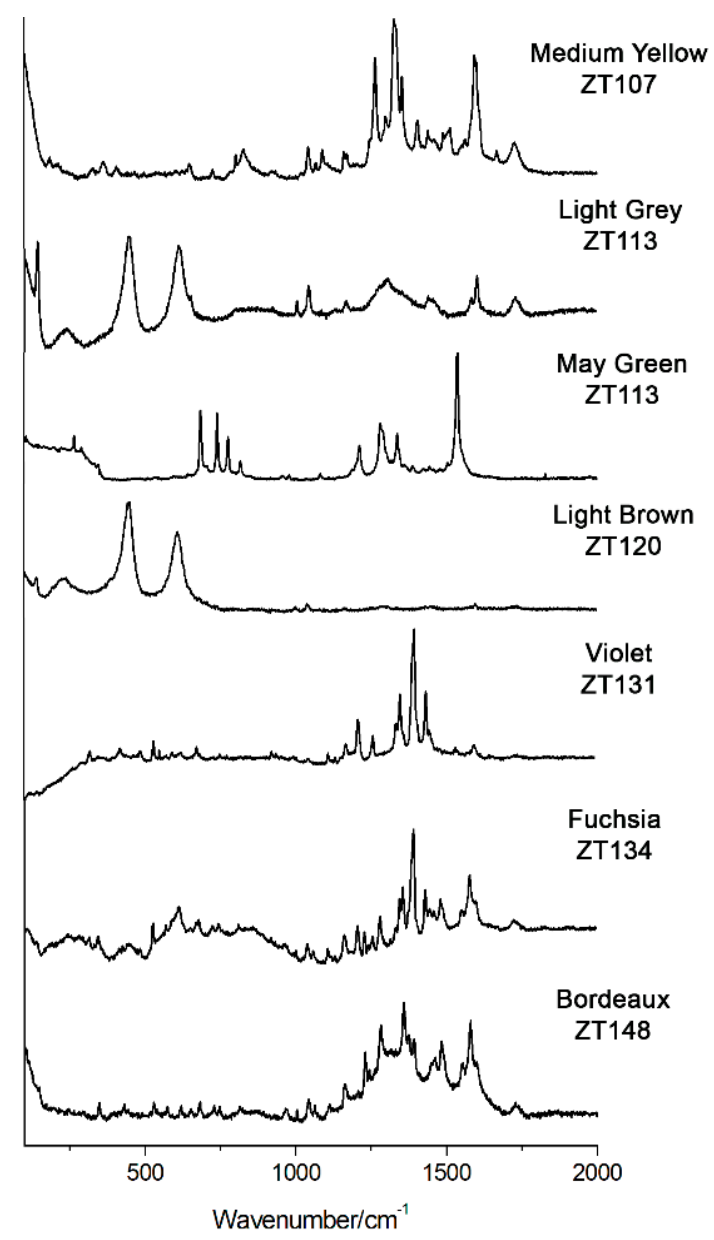

Figure 4. Raman spectra of the commercial sprays of the Decor brand.

Table 1. Elements identified in the commercial sprays. The major elements were considered up to $10 \%$ of relative presence. The elements with less than $1 \%$ were not included. The elements were ordered by taking into account their relative presence.

\begin{tabular}{|c|c|c|c|}
\hline Brand & Pigment & Major Elements & Minor Elements \\
\hline \multirow{3}{*}{ Titan } & Orange (554) & $\mathrm{Ti}, \mathrm{Fe}, \mathrm{Cl}$ & $\mathrm{Zn}, \mathrm{Pb}, \mathrm{Co}, \mathrm{Zr}, \mathrm{Ca}$ \\
\hline & White (566) & $\mathrm{Ti}$ & - \\
\hline & Yellow (529) & $\mathrm{Ti}, \mathrm{Fe}$ & $\mathrm{Ca}, \mathrm{Zr}, \mathrm{Co}, \mathrm{Cl}, \mathrm{Zn}$ \\
\hline \multirow{5}{*}{ Montana } & Vivid Red (RV-3001) & $\mathrm{Ti}, \mathrm{Fe}$ & $\mathrm{Ca}, \mathrm{Co}, \mathrm{Zr}, \mathrm{Zn}$ \\
\hline & Artic Blue (RV-29) & $\mathrm{Ti}$ & - \\
\hline & Dark Blue (RV-5005) & $\mathrm{Ti}, \mathrm{Cu}$ & $\mathrm{Si}, \mathrm{Ca}, \mathrm{Fe}$ \\
\hline & Druid Brown (RV-246) & $\mathrm{Ti}, \mathrm{Fe}$ & $\mathrm{Zr}$ \\
\hline & Cologno N. Green (RV-237) & $\mathrm{Ti}, \mathrm{Fe}$ & $\mathrm{Cl}, \mathrm{Ca}, \mathrm{Cu}, \mathrm{Si}, \mathrm{Zr}, \mathrm{Co}$ \\
\hline \multirow{7}{*}{ Decor Pintura } & Medium Yellow (ZT107) & $\mathrm{Bi}, \mathrm{V}$ & $\mathrm{Zr}, \mathrm{Co}, \mathrm{Zn}, \mathrm{Ca}, \mathrm{Ti}, \mathrm{Cl}$ \\
\hline & Light Grey (ZT113) & $\mathrm{Ti}$ & $\mathrm{Fe}, \mathrm{Si}, \mathrm{Zr}, \mathrm{Ca}$ \\
\hline & May Green (ZT129) & $\mathrm{Cl}, \mathrm{Cu}, \mathrm{Zr}, \mathrm{Ca}$ & $\mathrm{Ti}, \mathrm{Fe}, \mathrm{Co}$ \\
\hline & Light Brown (ZT120) & $\mathrm{Fe}$ & $\mathrm{Zr}, \mathrm{Si}, \mathrm{Zn}, \mathrm{Ca}, \mathrm{Co}$ \\
\hline & Violet (ZT131) & $\mathrm{Ti}, \mathrm{Fe}, \mathrm{Zr}$ & $\mathrm{Ca}, \mathrm{Co}, \mathrm{Zn}$ \\
\hline & Fuchsia (ZT134) & $\mathrm{Ti}$ & $\mathrm{Fe}, \mathrm{Zr}, \mathrm{Cl}, \mathrm{Co}, \mathrm{Ca}, \mathrm{Cr}$ \\
\hline & Bordeaux (ZT148) & $\mathrm{Cl}, \mathrm{Fe}, \mathrm{Ca}, \mathrm{Si}, \mathrm{Zr}$ & $\mathrm{Co}, \mathrm{Ti}, \mathrm{Zn}$ \\
\hline
\end{tabular}


Table 2. Compounds identified by means of Raman spectroscopy in the commercial sprays.

\begin{tabular}{|c|c|c|c|}
\hline Brand & Pigment & Composition & Raman Bands \\
\hline \multirow{5}{*}{ Titan } & Orange (554) & Pyrazoloquinazolone (PO67) & $\begin{array}{c}121,226,407,546,627,652,666,738,1012 \mathrm{~s}, 1117,1154 \\
1166,1216,1256 \mathrm{~s}, 1274,1298,1322,1340,1374,1413 \\
1532,1558 \mathrm{~s}, 1577,1603 \mathrm{~s} \mathrm{~cm}^{-1}\end{array}$ \\
\hline & \multirow{2}{*}{ White (566) } & Titanium oxide (Rutile) & $143,234,449 \mathrm{~s}, 612 \mathrm{~s} \mathrm{~cm}^{-1}$ \\
\hline & & Alkyd binder Binder & $1044,1168,1302,1447,1582,1602,1725 \mathrm{~cm}^{-1}$ \\
\hline & \multirow{2}{*}{ Yellow (529) } & Diarylide (PY13) & $\begin{array}{c}620,656,1146,1259 \mathrm{~s}, 1288 \mathrm{~s}, 1401 \mathrm{~s}, 1450,1493,1526 \\
1600 \mathrm{vs} \mathrm{cm}^{-1}\end{array}$ \\
\hline & & $\begin{array}{l}\text { Alkyd binder, most likely } \\
\text { CHS-Alkyd S } 471\end{array}$ & $1004,1044,1166,1727 \mathrm{~cm}^{-1}$ \\
\hline \multirow{10}{*}{ Montana } & \multirow[t]{2}{*}{ Vivid Red (RV-3001) } & Naphthol AS (PR170) & $\begin{array}{c}112,193,208,267,292,335,364,423,478,494,511,539 \\
574,611,732 \mathrm{~s}, 778,806,866,963 \mathrm{~s}, 1013,1043,1117,1141 \\
1167 \mathrm{~s}, 1208,1245,1288 \mathrm{~s}, 1334,1364 \mathrm{vs}, 1386,1423,1454 \\
1489,1513 \mathrm{~s}, 1552,1606 \mathrm{vs} \mathrm{cm}^{-1}\end{array}$ \\
\hline & & $\begin{array}{l}\text { Alkyd binder, most likely } \\
\text { CHS-Alkyd S } 471\end{array}$ & $1002,1043,1725 \mathrm{~cm}^{-1}$ \\
\hline & \multirow{3}{*}{ Artic Blue (RV-29) } & Phthalocyanine (PB15) & $\begin{array}{r}175,234,258,484,681 \mathrm{~s}, 748 \mathrm{~s}, 782,833,849,955,1110 \\
1145,1196,1218,1309,1344 \mathrm{~s}, 1453,1530 \mathrm{vs}, 1602 \mathrm{~cm}^{-1}\end{array}$ \\
\hline & & Titanium oxide (Rutile) & $142,234,447 \mathrm{~s}, 610 \mathrm{~s} \mathrm{~cm}^{-1}$ \\
\hline & & Alkyd binder & $1008,1042,1731 \mathrm{~cm}^{-1}$ \\
\hline & Dark Blue (RV-5005) & Phthalocyanine (PB15) & $\begin{array}{c}176,235,259,483,483,595,681 \mathrm{~s}, 719,747,832,847,954, \\
1038,1108,1144,1194,1216,1307,1342 \mathrm{~s}, 1412,1452 \mathrm{~s}, \\
1470,1483,1529 \mathrm{vs}, 1590 \mathrm{~cm}^{-1}\end{array}$ \\
\hline & \multirow{3}{*}{$\begin{array}{l}\text { Druid Brown } \\
\quad(\mathrm{RV}-246)\end{array}$} & Hematite & $226,244,292 \mathrm{~s}, 404 \mathrm{~s}, 484,610 \mathrm{~cm}^{-1}$ \\
\hline & & Goethite & $392,549 \mathrm{~cm}^{-1}$ \\
\hline & & $\begin{array}{l}\text { Alkyd binder, most likely } \\
\text { CHS-Alkyd S } 471\end{array}$ & $652,1004,1040,1578,1601 \mathrm{~cm}^{-1}$ \\
\hline & $\begin{array}{l}\text { Cologno N. Green } \\
\text { (RV-237) }\end{array}$ & Phthalocyanine (PG7) & $\begin{array}{c}194,234,266,598,641,684,740,775,818,951,975,1212 \\
1261,1282,1292,1337,1504,1537,1590 \mathrm{~cm}^{-1}\end{array}$ \\
\hline \multirow{8}{*}{$\begin{array}{l}\text { Decor } \\
\text { Pintura }\end{array}$} & \multirow[t]{2}{*}{$\begin{array}{l}\text { Medium Yellow } \\
\qquad(\mathrm{ZT} 107)\end{array}$} & Acetoacetic arylide (PY74) & $\begin{array}{c}186,329,363,406,648,803,829,923,1068,1090,1161 \\
1171,1265,1299,1327,1354,1406,1440,1491,1514,1563 \\
1595,1669 \mathrm{~cm}^{-1}\end{array}$ \\
\hline & & Alkyd binder & $726,1043,1727 \mathrm{~cm}^{-1}$ \\
\hline & \multirow[b]{2}{*}{ Light Grey (ZT113) } & Titanium white & $144,233,444 \mathrm{~s}, 611 \mathrm{~s} \mathrm{~cm}^{-1}$ \\
\hline & & $\begin{array}{l}\text { Alkyd binder, most likely } \\
\text { CHS-Alkyd S } 471\end{array}$ & $1005,1043,1303,1439,1602,1728 \mathrm{~cm}^{-1}$ \\
\hline & May Green (ZT129) & Phthalocyanine (PG7) & $\begin{array}{c}148,165,198,223,266,291,333,347,546,594,643,685 \mathrm{~s} \\
740 \mathrm{~s}, 776 \mathrm{~s}, 817,956,979,1083,1213 \mathrm{~s}, 1282 \mathrm{~s}, 1338 \mathrm{~s} \\
1388,1445,1538 \mathrm{vs}^{-1} \mathrm{~cm}^{-1}\end{array}$ \\
\hline & \multirow{3}{*}{ Light Brown (ZT120) } & Hematite & $226,246,293,411,610,1300 \mathrm{~cm}^{-1}$ \\
\hline & & Goethite & $387,549 \mathrm{~cm}^{-1}$ \\
\hline & & $\begin{array}{l}\text { Alkyd binder, most likely } \\
\text { CHS-Alkyd S } 471\end{array}$ & $1005,1042,1444,1583,1602,1724 \mathrm{~cm}^{-1}$ \\
\hline
\end{tabular}


Table 2. Cont.

\begin{tabular}{|c|c|c|c|}
\hline Brand & Pigment & Composition & Raman Bands \\
\hline & \multirow[t]{2}{*}{ Violet (ZT131) } & Dioxazine (PV23) & $\begin{array}{c}317,416,484,528 \mathrm{~s}, 591,672,724,748,921,934,990,1108 \\
1122,1131,1152,1167,1208 \mathrm{~s}, 1258 \mathrm{~s}, 1334 \mathrm{~s}, 1348 \mathrm{~s}, 1394 \\
\text { vs, } 1433 \mathrm{~s}, 1445,1593 \mathrm{~cm}^{-1}\end{array}$ \\
\hline & & $\begin{array}{l}\text { Alkyd binder, most likely } \\
\text { CHS-Alkyd S } 471\end{array}$ & $1003,1042 \mathrm{~cm}^{-1}$ \\
\hline & \multirow{3}{*}{ Fuchsia (ZT134) } & Dioxazine (PV23) & $\begin{array}{c}317,485,529,592,614,681,726,746,812,922,935,1110 \\
1133,1165,1208,1260,1335,1349,1394 \mathrm{~s}, 1433,1447 \\
1461,1581 \mathrm{~s} \mathrm{~cm}^{-1}\end{array}$ \\
\hline & & $\begin{array}{l}\text { Alkyd binder, most likely } \\
\text { CHS-Alkyd S } 471\end{array}$ & $1004,1042,1601,1726 \mathrm{~cm}^{-1}$ \\
\hline & & Unidentified & $347,442,1062,1231,1284,1359,1484,1553 \mathrm{~cm}^{-1}$ \\
\hline & \multirow[t]{2}{*}{ Bordeaux (ZT148) } & Naphthol AS (PR112) & $\begin{array}{l}348,431,529,575,620,682,720,747,814,967,1063,1163 \\
1231,1245,1358,1375,1393,1403,1485,1555,1581 \mathrm{~cm}^{-1}\end{array}$ \\
\hline & & Alkyd binder & $651,1004,1729 \mathrm{~cm}^{-1}$ \\
\hline
\end{tabular}

Regarding the "Decor" sprays, the composition changed considerably. As was mentioned previously, titanium was not present as a major element in all of these sprays, and other ones appeared, most likely indicating the use of a different type of formulation than in the previous brands, and even between different colours. In this sense, this brand had also more minor elements, indicating a more complex mixture. Regardless, the elemental analysis helped us to better understand the composition of the sprays. For example, in "Medium Yellow ZT107", the major elements were bismuth and vanadium, which could indicate the use of bismuth vanadate $\left(\mathrm{BiVO}_{4}\right)$, a common pigment used in the last decades [8]. However, in the Raman spectroscopy analysis, only acetoacetic arylide PY74, with the formula $\mathrm{C}_{18} \mathrm{H}_{18} \mathrm{~N}_{4} \mathrm{O}_{6}$, was identified as a pigment [15]. Considering the relative presence of the bismuth and vanadium, the mixture of both yellow pigments (PY74 and $\left.\mathrm{BiVO}_{4}\right)$ in this spray seems plausible. In the same way, in the cases of "May Green ZT129" and "Cologno N. Green RV-237", the presence of copper and chlorine as major elements could indicate the use of phthalocyanine green, which includes both elements in their structure. In addition, the PG7 pigment effectively was identified in both cases [15]. Regarding this point, it is necessary to remark that in the case of "Cologno N. Green RV-237", three Raman bands were observed at 1261, 1504, and $1590 \mathrm{~cm}^{-1}$; these bands are not found in the literature $[15,16,20]$. In fact, some discrepancies were observed in the literature, but the spectrum collected in the IRUG database [16] finally presented broad bands that could contain the bands that appear in this study, thus, the resolution of the obtained spectra most likely allowed us to obtain more than one band instead a broad one. Continuing with the chlorinated pigments, in "Bordeaux ZT148", chlorine was identified as major element due to the presence of naphthol AS PR112 pigment, a chlorinated pigment with the formula $\mathrm{C}_{24} \mathrm{H}_{16} \mathrm{Cl}_{3} \mathrm{~N}_{3} \mathrm{O}_{2}$ [15], but the presence of iron was also remarkable. Considering that the spray was red, the use of iron oxides mixed with the mentioned organic pigment was probable. The same case occurred with the "Vivid Red RV-3001" pigment, in which iron also was identified as major element, but when using Raman spectroscopy, another naphthol AS was identified as a pigment, in this case PR170 $\left(\mathrm{C}_{26} \mathrm{H}_{22} \mathrm{~N}_{4} \mathrm{O}_{4}\right)$, without chlorine [15]. Another chlorinated pigment was assumed in the "Orange 554" spray by XRF, and was identified as pyrazoloquinazolone $\mathrm{PO} 67\left(\mathrm{C}_{17} \mathrm{H}_{11} \mathrm{ClN}_{6} \mathrm{O}_{3}\right)$ pigment by Raman spectroscopy [15]. The same occurred for "Yellow 529", which was composed of diarylide PY13 pigment, with the formula $\mathrm{C}_{36} \mathrm{H}_{34} \mathrm{Cl}_{2} \mathrm{~N}_{6} \mathrm{O}_{4}$ [15]. Finally, the "Violet ZT131" and "Fuchsia ZT134" were very similar, as they were composed of the dioxazine PV23 pigment $\left(\mathrm{C}_{34} \mathrm{H}_{22} \mathrm{Cl}_{2} \mathrm{~N}_{4} \mathrm{O}_{2}\right)$ [15]. However, in the case of the latter, other bands were observed by Raman spectroscopy, but it was not possible to clearly identify the compound related to them. The presence of a monoazo or diazo red pigment could explain the bands $347,1359,1484$, and $1553 \mathrm{~cm}^{-1}$, 
but with an incomplete identification. In the XRF, it was also clear that the composition of both sprays was different even though the same pigment was present. In this sense, violet presented zinc, and fuchsia presented chlorine and chrome.

The binder used could be identified in many of the sprays. In all cases, they appeared to be alkyd binders [6,21,22], among the most common binders used in art due to their low cost, fast drying, and good optical properties. In this sense, the most repeated binder identified was Alkyd S471, with a $1042 \mathrm{~cm}^{-1}$ Raman band related to phthalate and a $1004 \mathrm{~cm}^{-1}$ band related to isophthalate [22]. Nevertheless, other alkyd binders were observed, with very similar Raman spectrum to S471 but slightly different, with the most relevant modifications being the appearance or disappearance of one of these two mentioned characteristic bands (1004 or $1042 \mathrm{~cm}^{-1}$ ), or the movement of the $1725-1732 \mathrm{~cm}^{-1}$ broad band, but related in any case to alkyd binders [22].

Taking all this into account, all the selected sprays could be identified, and although the complete composition was not achieved, information for pigments and binders was obtained, as well as for other additional compounds. This data increases the public database, with additional information to the usual information available as the brand or elemental composition, emphasizing the need to compile databases of real sprays and not just pure pigments. Moreover, all of this was important to do in a total open-access way, so the spectra of these studies are accessible in the Supplementary Materials (Table S1). Furthermore, as occurred with the PG7 pigment, it is important to provide not only the bands, but also the spectra, since, given the complexity of the spectra, discrepancies can be found in the literature, and without the raw spectra, the comparison is more difficult.

\subsection{Inks Samples from the Main Hall}

Regarding the sampled inks from the main hall, the analysis by XRF was more complicated due to the effect of the environment, as can be seen in Table 3 . In the first layers, it was possible to observe as major elements sulphur and calcium, the relative concentration of which decreased with the depth. In fact, sulphur in the inner layers appeared as a minor element. This was due to the action of atmospheric acid gases that have considerably affected the building $[23,24]$. In this sense, it is remarkable that the inks acted as a protective layer, minimizing the impact of the atmospheric $\mathrm{SO}_{2}$ on the original material, the result of wet or dry deposition due to the marine aerosol and usual fogs in the area, in contrast to the supposed increase of the degradation that these inks generate in the original materials [6]. This protection most likely will be the consequence of the high number of ink layers. Leaving aside this effect, elements such as silicon and potassium could be also related to the particulate matter, due to the marine aerosol and sand from the near beach $[1,18,24]$. Taking all of these in consideration, titanium again seems to be a relevant element in the spray's compositions. However, once again, rutile was observed by Raman spectroscopy only when it was used as pigment and not when used as additive, possibly due to the quantity present [16].

The study of each ink allowed its identification (Figure 5 and Table 4); starting from the external layer, the T1 ink presented lead in the elemental analysis, and by Raman spectroscopy, lead molybdate chromate pigment (PR104) was found, as can be seen in Figure 5 [15]. This pigment was composed of lead chromate, molybdate and sulphate $\left(\mathrm{PbCrO}_{4} \mathrm{PbMoO}_{4} \mathrm{PbSO}_{4}\right)$ [25]. The next two inks, T2 and T3, were identified as acetoacetic arylide (PY74), also observed in the measured commercial sprays. Even so, the T3 pigment was mixed with iron hydroxide, goethite, as it was assumed in view of the presence of iron in the elemental analysis [16]. This mixture possibly was formulated to obtain the desired tone. Following the layers, the next layer, T4, was identified as copper phthalocyanine (PB15), also identified in the commercial inks, although in this case copper was not found in the elemental analysis [15]. The T5 ink was clearly differentiated, since it was a light orange colour, and was identified as a mixture of two pigments, disazo pyrazolone PO34 and the previously mentioned PY74 [15]. Deeper, the T6 layer, again with a blue colour, showed the PB15 pigment, and in this measurement, copper was identified, as expected [15]. The next three layers (T7-T9) seemed to be very related. In the T7 layer, rutile was identified as 
a white pigment, along with the alkyd binder observed in the commercial sprays. The next colour was "Bone White" and was considered as a different layer, and in this case titanium oxide, rutile, as white pigment, PY74 as yellow pigment, and a weak band at $1003 \mathrm{~cm}^{-1}$, which could be related to the binder, were identified $[15,16]$. The differences between both inks were clear, however; the T9 was an ochre colour, and was identified as PY74 and iron oxide, goethite, confirmed by the major presence of iron in the elemental analysis $[15,16]$. So, the T8 layer could be a mixture of the other two layers (T7 and T9). Regarding the elemental analysis, there were some differences, but not enough to confirm if it was a different layer. Continuing, as in the case of commercial sprays, the green colour T10 seemed to be phthalocyanine due to the presence of copper and chloride in the elemental analysis. This observation was confirmed by Raman spectroscopy, which identified PG7 pigment, the copper-based phthalocyanine also observed in the commercial sprays [15]. This pigment also was identified in the final, inner layer, T12. However, the elemental analysis did not help in this case. Finally, the remaining ink, T11, was identified as PR48 or PR48:2 [15]. These pigments are classified as BONA, a name derived from $\beta$-hydroxynaphthoic acid, also known as 3-hydroxy-2-naphthoic acid. BONA is the ink component of different diazotized amines containing salt-forming groups [26]. This compound could precipitate with different cations, and depending on them, it could have a secondary number (PR48:X). In this case, the Raman spectra fitted better with the PR48 and PR48:2 pigments (the pigments with sodium and calcium, respectively) [15]. In this sense, the band observed at $1113 \mathrm{~cm}^{-1}$ was not present in the literature, but as in the case of the commercial spray "Cologno N. Green RV-237", it seemed to be the result of a better resolution obtained in this study, allowing us to identify this band, which can be found in the literature as a shoulder of the $1177 \mathrm{~cm}^{-1}$ Raman band. Regarding the elementary analysis, calcium was present, but it was not possible to avoid its presence as the effect of external agents or even as part of substrate, since it was the inner layer, and sodium is not well observed by XRF, making it impossible to determine exactly which pigment it was. Nevertheless, it did not have a negative impact on the restoration process.

Table 3. Elements identified in the sample's colours. The major elements were considered up to $10 \%$ of relative presence. The elements with less than $1 \%$ were not included. The elements were ordered by taking into account the relative presence.

\begin{tabular}{ccc}
\hline Name & Major Elements & Minor Elements \\
\hline (T1) Light Red & $\mathrm{Ca}, \mathrm{S}$ & $\mathrm{Fe}, \mathrm{Ti}, \mathrm{Pb}$ \\
\hline (T2) Light Green & $\mathrm{Ti}, \mathrm{Ca}$ & $\mathrm{S}, \mathrm{Fe}, \mathrm{Pb}, \mathrm{Si}, \mathrm{Zr}$ \\
\hline (T3) Dark Yellow & $\mathrm{Ca}, \mathrm{Fe}, \mathrm{S}$ & $\mathrm{Ti}$ \\
\hline (T4) Light Blue & $\mathrm{Ti}, \mathrm{Ca}, \mathrm{Fe}$ & $\mathrm{S}, \mathrm{Pb}, \mathrm{Bi}, \mathrm{Si}, \mathrm{K}$ \\
\hline (T5) Light Orange & $\mathrm{Ca}, \mathrm{Fe}, \mathrm{Ti}$ & $\mathrm{S}, \mathrm{Pb}, \mathrm{K}, \mathrm{Si}$ \\
\hline (T6) Dark Blue & $\mathrm{Ti}, \mathrm{S}, \mathrm{Ca}$ & $\mathrm{Pb}, \mathrm{Fe}, \mathrm{Cu}$ \\
\hline (T7) White & $\mathrm{Ti}, \mathrm{Ca}$ & $\mathrm{Fe}, \mathrm{Si}, \mathrm{S}$ \\
\hline (T8) Bone White & $\mathrm{Ti}, \mathrm{Fe}$ & $\mathrm{Cu}, \mathrm{Ca}, \mathrm{S}, \mathrm{Zr}$ \\
\hline (T9) Ochre & $\mathrm{Fe}, \mathrm{Ca}, \mathrm{S}, \mathrm{Ti}$ & $\mathrm{Cu}, \mathrm{Pb}$ \\
\hline (T10) Dark Green & $\mathrm{Ca}, \mathrm{Ti}, \mathrm{Fe}, \mathrm{S}$ & $\mathrm{Cl}, \mathrm{Si} \mathrm{Cu}, \mathrm{Pb}, \mathrm{K}$ \\
\hline (T11) Purple & $\mathrm{Ti}, \mathrm{Fe}, \mathrm{Ca}$ & $\mathrm{S}, \mathrm{Bi}, \mathrm{Si}, \mathrm{Mn}, \mathrm{Zn}$ \\
\hline (T12) Light Yellow & $\mathrm{Ti}, \mathrm{Fe}$ & $\mathrm{Ca}, \mathrm{S}, \mathrm{Si}, \mathrm{As}$ \\
\hline
\end{tabular}



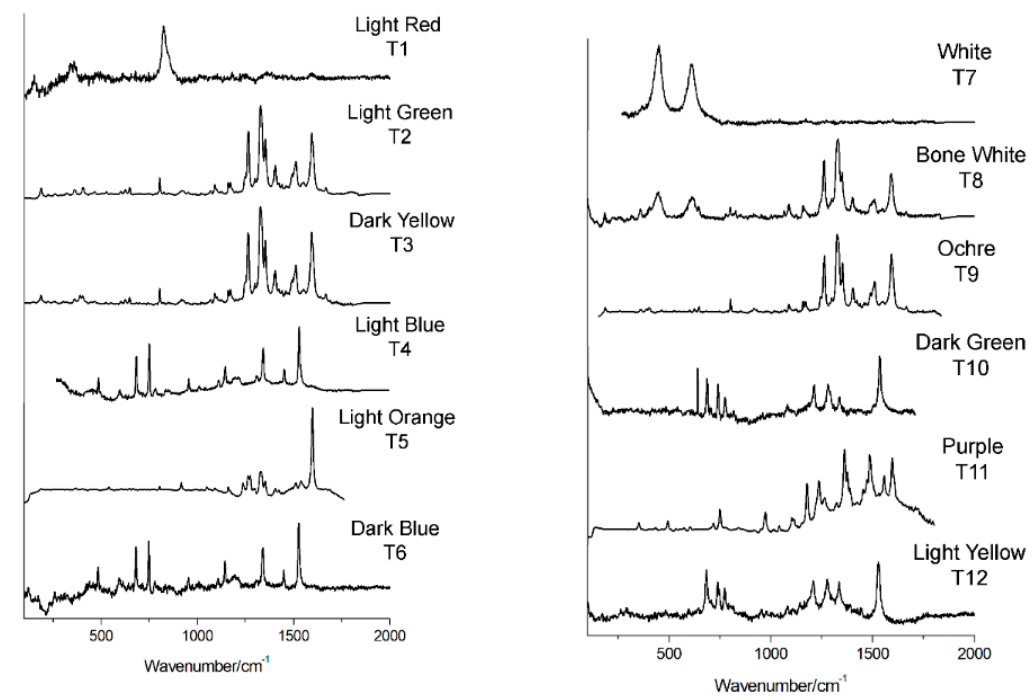

Figure 5. Raman spectra of the sampled inks in the main hall of the Punta Begoña Galleries, with T1 being the most external layer, and T12 the innermost layer.

Table 4. Compounds identified by means of Raman spectroscopy in the main hall samples.

\begin{tabular}{|c|c|c|}
\hline Name & Composition & Raman Bands \\
\hline (T1) Light Red & Lead molybdate chromate (PR104) & $151,337,357,823 \mathrm{~s}, 849 \mathrm{sh} \mathrm{cm}^{-1}$ \\
\hline (T2) Light Green & Acetoacetic arylide (PY74) & $\begin{array}{c}187,224,260,319,361,404,465,524,601,624,646,802,846,917 \\
1018,1067,1089,1160,1171,1264 \mathrm{~s}, 1299,1327 \mathrm{vs}, 1353 \mathrm{~s}, 1404 \\
1423,1439,1459,1512,1551,1593 \mathrm{~s}, 1668 \mathrm{~cm}^{-1}\end{array}$ \\
\hline \multirow[t]{2}{*}{ (T3) Dark Yellow } & Acetoacetic arylide (PY74) & $\begin{array}{c}186,260,359,402,464,524,601,623,646,742,802,846,917,1017 \\
1066,1089,1160,1170,1263 \mathrm{~s}, 1298,1327 \mathrm{vs}, 1352 \mathrm{~s}, 1403,1423, \\
1439,1459,1490,1511,1551,1593 \mathrm{~s}, 1668 \mathrm{~cm}^{-1}\end{array}$ \\
\hline & Goethite & $301,387,549 \mathrm{~cm}^{-1}$ \\
\hline (T4) Light Blue & Phthalocyanine (PB15) & $\begin{array}{c}290,483,596,642,682 \mathrm{~s}, 719,748 \mathrm{v} \mathrm{s}, 782,834,846,954,1009,1110 \\
1144 \mathrm{~s}, 1197,1210,1307,1342,1451,1529 \mathrm{vs} \mathrm{cm}^{-1}\end{array}$ \\
\hline \multirow[b]{2}{*}{ (T5) Light Orange } & Disazo pyrazolone (PO34) & $\begin{array}{c}294,369,392,539,669,768,915,1048,1159,1188,1237,1273,1289 \\
1298,1422,1475,1537,1598 \mathrm{vs}, 1654 \mathrm{~cm}^{-1}\end{array}$ \\
\hline & Acetoacetic arylide (PY74) & $\begin{array}{c}186,224,259,358,403,600,322,645,801,953,1018,1089,1124 \\
1159,1263,1298,1327 \text { vs, } 1351,1404,1438,1498,1511,1598 \mathrm{~s}, 1666 \\
\mathrm{~cm}^{-1}\end{array}$ \\
\hline (T6) Dark Blue & Phthalocyanine (PB15) & $\begin{array}{c}290 \mathrm{vw}, 483,594,643 \mathrm{vw}, 680 \mathrm{~s}, 715 \mathrm{vw}, 748 \mathrm{~s}, 780,834,855,954, \\
1008 \mathrm{vw}, 1108,1144,1195,1307,1342 \mathrm{~s}, 1450,1529 \mathrm{vs} \mathrm{cm}^{-1}\end{array}$ \\
\hline \multirow{2}{*}{ (T7) White } & Titanium white & $448,606 \mathrm{~cm}^{-1}$ \\
\hline & Alkyd binder & $999,1042,1172,1308,1599 \mathrm{~cm}^{-1}$ (very weak) \\
\hline \multirow{3}{*}{ (T8) Bone White } & Acetoacetic arylide (PY74) & $\begin{array}{c}186,264,314,359,404,645,802,827,915,953,1018,1066,1090 \\
1125,1160,1263 \text { vs, } 1300,1331 \text { vs, } 1351 \text { vs, } 1403,1511,1549,1592 \\
\text { vs, } 1637,1667 \mathrm{~cm}^{-1}\end{array}$ \\
\hline & Titanium white & $447 \mathrm{~s}, 612 \mathrm{~s} \mathrm{~cm}^{-1}$ \\
\hline & Alkyd binder & $1003 \mathrm{~cm}^{-1}$ (very weak) \\
\hline \multirow[t]{2}{*}{ (T9) Ochre } & Acetoacetic arylide (PY74) & $\begin{array}{c}187,359,403,465,601,624,646,802,916,1018,1067,1089,1160 \\
1171,1264 \mathrm{~s}, 1298,1327 \mathrm{vs}, 1353 \mathrm{~s}, 1404,1423,1439,1460,1490 \\
1512 \mathrm{~s}, 1552,1593 \mathrm{~s}, 1668 \mathrm{~cm}^{-1}\end{array}$ \\
\hline & Goethite & $385 \mathrm{~cm}^{-1}$ \\
\hline
\end{tabular}


Table 4. Cont.

\begin{tabular}{|c|c|c|}
\hline Name & Composition & Raman Bands \\
\hline (T10) Dark Green & Phthalocyanine (PG7) & $\begin{array}{c}100,224,685 \mathrm{~s}, 740 \mathrm{~s}, 774 \mathrm{~s}, 817,959,1080,1212 \mathrm{~s}, 1281 \mathrm{~s}, 1337 \mathrm{~s}, \\
1535 \mathrm{vs} \mathrm{cm}^{-1}\end{array}$ \\
\hline (T11) Purple & Bona (PR48 Na or PR48:2 Ca) & $\begin{array}{c}350,412,493,532,572,601,717,748,972,1040,1104,1113,1177 \\
1236,1236,1263,1323,1361,1375,1387,1454,1473,1486,1557 \\
1596 \mathrm{~cm}^{-1}\end{array}$ \\
\hline (T12) Light Yellow & Phthalocyanine (PG7) & $\begin{array}{c}100,264,292,684,740,773,956,1081,1209,1277,1337,1442,1529 \mathrm{~s} \\
\mathrm{~cm}^{-1}\end{array}$ \\
\hline
\end{tabular}

In summary, the composition of the sprays was not just organic, but a mixture of organic and inorganic compounds. In addition, there were some pigments, such as PY74 and PB15, that seemed to be the most common [15]. For restoration purposes, and considering the number of ink layers in the main hall, one or more products will most likely be needed to remove them.

\section{Conclusions}

The existing databases have been slightly expanded, including elementary information, missed Raman bands in the literature, and the commercial brands. However, more efforts should be made in this regard, above all to ensure that all this information is provided for free through open-access publications. For this reason, the creation of databases of specific sprays, not only of pure pigments, is recommended to help understand them correctly. These databases could help in restoration works of street art, and even to determine the authorships, or in restoration of vandalism actions despite the trademark's secrecy.

Regarding the specific results of this work, even if the characterization of the sampled inks was complicated, it allowed us to identify most of the components of the sprays studied, not just the pigments, despite not having much information from the manufacturers. This information will serve to direct the graffiti-removal protocols to use the most appropriate products. Moreover, the relevance of the elemental analysis, which is generally avoided in graffiti analysis, provided relevant information, and assisted in the identification of the used pigments and other compounds, and also in observing the impact suffered by the building under study.

Thus, this work points out the importance of the study of modern inks before their removal and the need to promote open-access databases that include the elemental and brand information to help in future characterization and diagnostic practices.

Supplementary Materials: The following are available online at https:/ / www.mdpi.com/article/10 $.3390 /$ app11188640/s1, Table S1: A listing of all the .spc spectral data.

Author Contributions: Experimental analysis and interpretation, I.E., N.P.-T. and E.L.; writingoriginal draft, N.P.-T.; supervision, M.D.R.-L., G.A., and J.M.M.; project administration, G.A. and J.M.M.; funding acquisition, G.A. and J.M.M. All authors have read and agreed to the published version of the manuscript.

Funding: This work was supported by the DEMORA (Grant No. PID2020-113391GB-I00) project funded by the Spanish Agency for Research AEI (MICINN/FEDER-UE), and by the cooperation agreement between the University of the Basque Country and the City Council of Getxo (OTRI 2019-0316).

Institutional Review Board Statement: Not applicable.

Informed Consent Statement: Not applicable.

Acknowledgments: The authors wish to acknowledge the professional support of the Interdisciplinary Thematic Platform from CSIC Open Heritage: Research and Society (PTI-PAIS).

Conflicts of Interest: The authors declare no conflict of interest. 


\section{References}

1. Lama, E.; Prieto-Taboada, N.; Etxebarria, I.; Bermejo, J.; Castro, K.; Arana, G.; Rodrí-guez-Laso, M.D.; Madariaga, J.M. Spectroscopic characterization of xx century mural paintings of punta begoña's galleries under conservation works. Microchem. J. 2021, 168, 106423. [CrossRef]

2. Galerías Punta Begoña. Galerías Punta Begoña. 2019. Available online: https:/ / puntabegona.getxo.eus / (accessed on 17 July 2021).

3. European Commission. Real Long-Term Working Conditions of Anti-Graffiti and Self-Cleaning Coatings for Their ImpleMentation in the Protection of the European Cultural Heritage. 2017. Available online: https://cordis.europa.eu/project/id/62 2417/ es (accessed on 17 July 2021).

4. European Commission. Development of a New Antigraffiti System, Based on Traditional Concepts, Preventing Damage of Architectural Heritage Materials. 2012. Available online: https:/ / cordis.europa.eu/project/id/513718/reporting/es (accessed on 17 July 2021).

5. European Commission. InnovativE Anti-Graffiti Product for Application in the Cultural Heritage of Europe. 2012. Available online: https:/ / cordis.europa.eu/project/id/513718/reporting (accessed on 17 July 2021).

6. Gomes, V.; Dionísio, A.; Pozo-Antonio, J.S. Conservation strategies against graffiti vandalism on Cultural Heritage stones: Protective coatings and cleaning methods. Prog. Org. Coat. 2017, 113, 90-109. [CrossRef]

7. Rivas, T.; Pozo, S.; Fiorucci, M.P.; López, A.J.; Ramil, A. Nd:YVO4 laser removal of graffiti from granite. Influence of paint and rock properties on cleaning efficacy. Appl. Surf. Sci. 2012, 263, 563-572. [CrossRef]

8. Cortea, I.M.; Ratoiu, L.; Rădvan, R. Characterization of spray paints used in street art graffiti by a non-destructive multi-analytical approach. Color Res. Appl. 2021, 46, 183-194. [CrossRef]

9. Germinario, G.; van der Werf, I.D.; Sabbatini, L. Chemical characterisation of spray paints by a multi-analytical (Py/GC-MS, FTIR, $\mu$-Raman) approach. Microchem. J. 2016, 124, 929-939. [CrossRef]

10. Sánchez Pons, M. Acercamiento a la evolución histórica y tecnológica de los materiales pictóricos empleados en el grafiti y arte urbano. GEC 2016, 10, 146-159. [CrossRef]

11. Bosi, A.; Ciccola, A.; Serafini, I.; Guiso, M.; Ripanti, F.; Postorino, P.; Curini, R.; Bianco, A. Street art graffiti: Dis-covering their composition and alteration by FTIR and micro-Raman spectroscopy. Spectrochim. Acta A 2020, 225, 117474. [CrossRef] [PubMed]

12. Caggiani, M.C.; Cosentino, A.; Mangone, A. Pigments Checker version 3.0, a handy set for conservation scientists: A free online Raman spectra database. Microchem. J. 2016, 129, 123-132. [CrossRef]

13. Madariaga, J.M. Analytical chemistry in the field of cultural heritage. Anal. Methods 2015, 7, 4848-4876. [CrossRef]

14. Madariaga, J.M. Analytical Strategies for Cultural Heritage Materials and their Degradation. R. Soc. Chem. 2021, P001. [CrossRef]

15. Fremout, W.; Saverwyns, S. Identification of synthetic organic pigments: The role of a comprehensive digital Raman spectral library. J. Raman Spectrosc. 2012, 43, 1536-1544. [CrossRef]

16. Infrared \& Raman Users Group (IRUG). Spectral Database: Organic Dyes and Pigments. 2021. Available online: http://www. irug.org/search-spectral-database/spectra-index?sortHeader=data_type_raman (accessed on 17 July 2021).

17. Noguera-Cámara, J.; Amor-García, R.L. Conservation Issues in Modern and Contemporary Murals; Sánchez, M., Shank, W., Fuster, L., Eds.; Cambridge Scholars Publishing: Cambridge, UK, 2015; pp. 166-183.

18. Madariaga, I.; Lama, E.; Calparsoro, E.; Prieto-Taboada, N.; Arana, G.; Laso, M.D.R.; Madariaga, J.M. Enhancement and recovery of the tiles affected by atmospheric pollutants in the Galleries of Punta Begoña, Getxo (Bizkaia). Boletín Soc. Española Cerámica Vidr. 2019, 58, 161-170. [CrossRef]

19. Dahlen, M.A. The Phthalocyanines A New Class of Synthetic Pigments and Dyes. Ind. Eng. Chem. 1939, 31, 839-847. [CrossRef]

20. Scherrer, N.C.; Stefan, Z.; Francoise, D.; Annette, F.; Renate, K. Synthetic organic pigments of the 20th and 21st century relevant to artist's paints: Raman spectra reference collection. Spectrochim. Acta A 2009, 73, 505-524. [CrossRef] [PubMed]

21. Wiesinger, R.; Pagnin, L.; Anghelone, M.; Moretto, L.M.; Orsega, E.F.; Schreiner, M. Pigment and Binder Concen-trations in Modern Paint Samples Determined by IR and Raman Spectroscopy. Angew. Chem. Int. Ed. 2018, 57, 7401-7407. [CrossRef] [PubMed]

22. Honzíček, J.; Matušková, E.; Voneš, Š.; Vinklárek, J. MaterialsHelmet Phthalocyaninato Iron Complex as a Primary Drier for Alkyd Paints. Materials 2021, 14, 1220. [CrossRef] [PubMed]

23. García-Florentino, C.; Maguregui, M.; Morillas, H.; Balziskueta, U.; Azcarate, A.; Arana, G.; Madariaga, J.M. Port-able and Raman imaging usefulness to detect decaying on mortars from Punta Begoña Galleries (Getxo, North of Spain). J. Raman Spectrosc. 2016, 47, 1458-1466. [CrossRef]

24. Prieto-Taboada, N.; Ibarrondo, I.; Gómez-Laserna, O.; Martinez-Arkarazo, I.; Olazabal, M.A.; Madariaga, J.M. Buildings as repositories of hazardous pollutants of anthropogenic origin. J. Hazard. Mater. 2013, 248-249, 451-460. [CrossRef] [PubMed]

25. Buzzini, P.; Massonnet, G.; Sermier, F.M. The micro Raman analysis of paint evidence in criminalistics: Case studies. J. Raman Spectrosc. 2006, 37, 922-931. [CrossRef]

26. Jaffe, E.E. Pigments, Organic. Kirk-Othmer Encyclopedia of Chemical Technology 2004. 